\title{
Guideline Education Program about Nursing Ethics in Pediatric Oncology Unit: Effect on Nurses' Knowledge and Practice
}

\author{
Madiha Hassan Bayoumi ${ }^{1}$, Fawzia Farouk Kamel ${ }^{2}$, Amal Abdelrazik Fathalla $^{3}$ \\ ${ }^{1}$ Pediatric Nursing Department, Faculty of Nursing, Benha University \\ ${ }^{2}$ Nursing administration Department, Faculty of Nursing, Benha University \\ ${ }^{3}$ Pediatric Nursing Department, Faculty of Nursing, Menoufia University
}

\begin{abstract}
The work nature of nurses in pediatric oncology unit necessitates ethical care more than routine care. Therefore, nurses require knowledge about nursing ethics in this area to guide their practice in a competent manner.

Aim of this study was to evaluate the effect of guideline education program about nursing ethics on nurses' knowledge and practice in pediatric oncology unit.

Setting: The study was conducted in Oncology/Hematology Unit at Benha Specialized Pediatric Hospital. Research design: Quasi-experimental design was utilized.

Sample: A purposive sample of 32 nurses who worked at the previously mentioned setting.

Tools: Data were collected through two main tools; (I) a structured interview ethical responsibilities questionnaire sheet, it was consisted of two parts; personal characteristics of the studied nurses and nurses' knowledge about ethical behavior in pediatric oncology unit. (II) Observational checklist for assessing nurses' practice regarding application of ethical principles toward dealing with children in pediatric oncology unit. Results: of this study showed that, mean age of the studied nurses was $25.97 \pm 4.99$ years. There were highly statistical significant differences in relation to nurses' knowledge and practice regarding their ethical responsibilities in pediatric oncology unit at pre and post-program intervention.

Conclusion: this study concluded that nurses' knowledge and practice toward their ethical responsibilities in pediatric oncology unit was improved after implementation of the guideline education program. Recommendation: Encourage nurses to attend training courses about their ethical responsibilities toward children in oncology unit.
\end{abstract}

Key words: Pediatric Oncology, Ethics, Nurses' knowledge, Nurses' Practice

\section{Introduction:}

Pediatric oncology is a specialty discipline in medicine concerned with diagnosing and treating children, usually up to the age of 18, with various types of cancers (Ellis-Christensen, 2010). Caring for a child with cancer is one of the most technically and emotionally difficult areas in nursing. Not only as the nurse dealing with children and adolescents who hurt, but also as she must reassure and educate families, balance a multitude of other health care professionals and keep up with ever-changing nursing practice and care (McLennon et al., 2013 and Stegenga, 2015).

Diagnosis and treatment of cancer are considered difficult times for children and their families. During diagnosis and treatment, children have tests and procedures that are new, painful and often scary, so ethical issues should be put into consideration during care (Children's Oncology Group, 2010 and American Cancer Society, 2012). Therefore, ethics or ethical codes are guidelines that orient nurses and ensure that their decisions are in accordance with the values of the professional system. These codes show that there is a connection among values, patients' rights and nurses' duties and practice (Momennasab et al., 2015).

The ethical practices that govern oncology nursing are fall into the following categories; nonmalfeasance, beneficence, respect each person as a person and respect individual autonomy, treat patients as they have a right to be treated and treated patients fairly (i.e. principles of distributive justice) (Sundean \& McGrath, 2013). Therefore, ethical knowledge helps professionals to justify what is or is not correct and appropriate professional practice to conduct. Also it promotes respect for and promotion of the principles of bioethics and the rights of health services users, which are crucial elements in humanized care (Erickson \& Payne, 2016).

In pediatric oncology, decisions regarding the best interest of the patient are further complicated by the inability of children to make informed decisions. At times, the desire of the parents to prolong the life of their child may be so overwhelming that the quality of the child's life is ignored, even when there is little hope for a cure. The nursing staff is often the first to become aware of this shift in what is truly in the best interest of the patient. So, good nursing practice requires that practical efficacy and ethics are given equal consideration (American Medical Association, 2010 and Blogger \& Moore, 2010). 
Nurses in pediatric oncology unit are primarily responsible for the treatment and care for children with cancer. In some instances, they are also known as pediatric hematology/oncology nurses, where they may care for children with blood disorders (Association of Pediatric Hematology/Oncology Nurses, 2011). However, as nurses are considered moral agents they should play a valuable role in promoting ethical care for children and families. Therefore, nurses should be provided with the clinical, educational and administrative supports required which enabling them to fulfill this role (Kopelman, 2013).

However, nursing profession requires knowledge about ethics to guide competent performance, as the nature of this profession necessitates ethical care more than routine care. Worldwide, definition of professional ethic code has been done based on human and ethical issues in the communication between nurse and patient. To improve all dimensions of nursing, it is important to respect ethic codes (Mohajjel-Aghdam et al., 2013). So, attention to ethical principles through health care staff education, case discussions, or ethics consultations will help clarify directions, boundaries, goals, processes and sometimes conflicts, thereby smoothing the illness experience for patients, families and staff (Kearney \& Lederberg, 2014).

\section{Significance of the Study}

In pediatric oncology unit, there are numerous ethical issues which arise in the care of oncology patients. Identifying and understanding these ethical issues surrounding patient care is the first step for nurses in making ethical decisions in their practice. Thus, providing ethics education to nurses, dealing with frequent or disturbing ethical issues specific to their nursing practice, rather than general issues, can be effective to support nurses to make appropriate decisions based on the complex reality of clinical situations (Seoul et al., 2014 and American Nurses Association, (2015).

\section{Aim of the Study}

The current study was aimed to evaluate the effect of guideline education program about nursing ethics on nurses' knowledge and practice in pediatric oncology unit. This aim achieved through:

- Assessing nurses' knowledge and practice regarding their ethical responsibilities toward children in pediatric oncology unit. practice.

- Designing and implementing guideline education program based on level of nurses' knowledge and

- Evaluating the effect of guideline education program on nurses' knowledge and practice regarding their ethical responsibilities toward children in pediatric oncology unit.

\section{Research hypothesis:}

The researchers hypothesized that nurses' knowledge and practice toward their ethical responsibilities in pediatric oncology unit will be improved significantly after implementation of the guideline education program than before.

\section{Setting:}

Research Design:

\section{Material And Methods}

Quasi-experimental research design was utilized to fulfill the aim of this study

The study was conducted in Oncology/Hematology Unit at Benha Specialized Pediatric Hospital. This unit includes children suffering from cancer and hematological disorders such as; sickle cell anemia, thalassemia,...etc. It contains 8 beds in the ward for management of children with hematological disorders and 17 beds for children with cancer. Nurses who are working in Oncology/Hematology Unit are responsible for providing care for all those children.

\section{Sample}

A purposive sample of 32 nurses who worked in the previously mentioned setting and met the study criteria were involved in the current study.

\section{Inclusion Criteria}

Nurses who are included in the present study should fulfill the following criteria:

- Their years of experience in pediatric oncology unit not less than one year.

- Accept to participate in the study.

Tools of data collection:

Two tools were used in this study for data collection; 
Tool (I): Structured interview ethical responsibilities questionnaire sheet. It was developed by the researchers and it encompassed two main parts:

Part (1): Personal characteristics of the studied nurses. It contained: age, job, qualification, years of experience in pediatric oncology unit and previous training courses about ethical responsibilities regarding children in pediatric oncology unit.

Part (2): Nurses' knowledge about ethical behavior in pediatric oncology unit. It was developed by the researchers based on review of related literature (Cherry \& Jacob, 2008; Ahmed, 2010; Kumar et al., 2011 and Aliyu etal., 2015) and it contained ten essay questions and ten true or false questions about; meaning of ethics in nursing, ethical responsibilities during caring for children in pediatric oncology unit regarding priority and privacy, ethical issues confront nurses during dealing with children related to ethical principles, responsibility of oncology nurses to keep information about child's illnesses and treatment: confidential, ....etc.

\section{Scoring system:}

The scoring system for nurses' knowledge was as follow; two scores were given for correct answer and one for the incorrect. The scoring levels were arranged as follow; less than $65 \%$ for poor knowledge, from $65 \%$ to less than $75 \%$ for average knowledge and $\geq 75 \%$ for good nurses' knowledge.

Tool (II): Observational checklist for nurses' practice regarding application of ethical principles when providing care for children in pediatric oncology unit. It was developed by the researchers based on review of related literature (Cherry \& Jacob, 2008; Mohamed, 2006; Ahmed, 2010 and Kumar et al., 2011). It consisted of 31 principles related to nursing ethics in pediatric oncology unit. It was divided into 6 categories; Ethical principles related to child's clinical integrity (11 items), Ethical principles related to child's respect (6 items), Ethical principles related to child's privacy (4 items), Ethical principles related to child's confidentiality ( 3 items), Ethical principles related to beneficence ( 3 items), and Ethical principles related to justify (4 items).

\section{Scoring system:}

Each item was assigned score (2) if the nurse follow the ethical principles when providing care for children and (1) if she doesn't. The range of total scores expressed as follow; competent practice $\geq 75$, meanwhile incompetent practice from $<75$.

\section{Guideline education program:}

It was constructed by the researchers after reviewing the related literature which based on nurses' knowledge and practice regarding their ethical responsibilities in pediatric oncology unit.

\section{Validity and Reliability}

The data collection tools were revised for comprehensiveness, appropriateness, and legibility by a panel of five experts in the field of pediatric and administration nursing to test the face and content validity. According to their revision, few modifications in the face validity were carried out.

Regarding reliability, the reliability coefficients' alpha between questions about nurses' knowledge was 0.719 . Meanwhile, the reliability coefficients' alpha between items about ethical practice was 0.78

\section{Ethical considerations:}

The participated nurses were instructed by the researchers about aim and benefits of the study and verbal agreement was taken before data collection. The participants were assured that their participation was totally voluntary. The nature of commitment in terms of time and form of participation like filling a questionnaire was clearly indicated. Information obtained was treated with utmost confidentiality. The participants were informed that they have the right to withdraw from the study at any time without giving any reasons. No identifiers like name of the participant were indicated on the questionnaire.

\section{Pilot study:}

Pilot study was conducted on $10 \%$ from the total number of sample (4 nurses) in order to identify the clarity, time needed and applicability of the study tools.

\section{Procedure of data collection}

An official permission was obtained from the Dean of Faculty of Nursing, Benha University to conduct the study and collect the necessary data. Before starting the work, orienting nurses with the study and its purposes was done in order to obtain their oral consent to participate in the study. Each nurse was interviewed individually to complete filling in the study tool, the interview took approximately 20-30 minutes for knowledge and 30-45 minutes for practice depending upon response of the nurses. Data were collected during the period from the beginning of April to the end of September, 2015. Nurses were divided into small groups, 
the average number of observed nurses was 5-6 nurses, they were interviewed and observed three times/week during morning and afternoon shifts. Firstly, nurse' knowledge and practice were evaluated before the beginning of guideline program intervention. Then, instructional handouts about ethics in pediatric oncology unit distributed to the participants after designed and developed by the researchers in simple Arabic language, . After completion of the guideline program intervention, nurse' knowledge and practice were re-evaluated by the same tools.

\section{Statistical design:}

A compatible personal computer (PC) was used to store and analyze data. The Statistical Package for Social Studies (SPSS), version 20.0 was used. Data were coded and summarized using means and standard deviation for quantitative variables and percentage distribution for qualitative variables. Comparison of means was performed using paired-sample t-test. Correlation among variables was done using Pearson correlation coefficient (Pearson's $r$, test) to measure of the strength and direction of the linear relationship between the study variables' means and standard deviations.

\section{Results}

According to personal characteristics of the studied nurses the current study revealed that, the mean age of nurses were $25.97 \pm 4.99$ years, $31.3 \%$ had bachelor degree of nursing. Three quarters of nurses $(75 \%)$ had specialty in pediatric oncology and $56.2 \%$ of them had 3-5 years of experience. Meanwhile, all of them (100\%) didn't attend any training courses regarding ethical responsibilities in pediatric oncology unit and they reported that there was an ethical committee in the hospital but its role is not enabled.

Table (1): Distribution of nurses' knowledge regarding nursing ethics in pediatric oncology unit at pre/postprogram Implementation $(\mathrm{n}=32)$

\begin{tabular}{|c|c|c|c|c|c|c|c|c|c|c|}
\hline \multirow[t]{3}{*}{ Nursing ethics } & \multicolumn{4}{|c|}{ Pre- implementation } & \multicolumn{4}{|c|}{ Post- implementation } & \multirow[t]{3}{*}{$\mathbf{X}^{2}$} & \multirow{3}{*}{$\begin{array}{l}\mathbf{P}- \\
\text { value }\end{array}$} \\
\hline & \multicolumn{2}{|c|}{ Correct } & \multicolumn{2}{|c|}{ Incorrect } & \multicolumn{2}{|c|}{ Correct } & \multicolumn{2}{|c|}{ Incorrect } & & \\
\hline & No. & $\%$ & No. & $\%$ & No. & $\%$ & No. & $\%$ & & \\
\hline Meaning of ethics & 7 & 21.9 & 25 & 78.1 & 24 & 75 & 8 & 25 & 18.08 & $0.000 * *$ \\
\hline Importance of ethics in nursing & 14 & 43.8 & 18 & 56.2 & 26 & 81.2 & 6 & 18.8 & 9.60 & $0.002 *$ \\
\hline Types of ethics & 9 & 28.1 & 23 & 71.9 & 27 & 84.4 & 5 & 15.6 & 20.57 & $0.000 * *$ \\
\hline Principles of ethical issues & 13 & 40.6 & 19 & 59.4 & 30 & 93.8 & 2 & 6.2 & 20.48 & $0.000 * *$ \\
\hline Element of code of ethics & 8 & 25 & 24 & 75 & 30 & 93.8 & 2 & 6.2 & 31.35 & $0.000 * *$ \\
\hline $\begin{array}{l}\text { Difference between law and } \\
\text { ethics }\end{array}$ & 10 & 31.2 & 22 & 68.8 & 27 & 84.4 & 5 & 15.6 & 18.51 & $0.000 * *$ \\
\hline Criteria of nursing profession & 5 & 15.6 & 27 & 84.4 & 28 & 87.5 & 4 & 12.5 & 33.09 & $0.000 * *$ \\
\hline $\begin{array}{l}\text { Characteristic of professional } \\
\text { nurse }\end{array}$ & 14 & 43.8 & 18 & 56.2 & 30 & 93.8 & 2 & 6.2 & 12.00 & $0.001 * *$ \\
\hline $\begin{array}{l}\text { Ethical responsibilities of nurses } \\
\text { in pediatric oncology unit }\end{array}$ & 9 & 28.1 & 23 & 71.9 & 26 & 81.2 & 6 & 18.8 & 18.22 & $0.000 * *$ \\
\hline $\begin{array}{l}\text { Pediatric patient rights in } \\
\text { oncology unit }\end{array}$ & 9 & 28.1 & 23 & 71.9 & 31 & 96.6 & 1 & 3.1 & 7.58 & $0.006^{*}$ \\
\hline
\end{tabular}

* Statistically significant at $\mathbf{P}<0.05 \quad * * A$ highly statistical significant at $\mathbf{P} \leq 0.001$

Table (1) clarified that there were statistical significant differences regarding nurses' knowledge about nursing ethics at pre- and post-program implementation.

Table (2): Distribution of Nurses' Knowledge regarding Ethical Responsibilities in Pediatric Oncology Unit at Pre/Post Program Implementation $(n=32)$

\begin{tabular}{|c|c|c|c|c|c|c|c|c|c|c|}
\hline \multirow{3}{*}{$\begin{array}{l}\text { Nursing knowledge regarding } \\
\text { ethical responsibilities }\end{array}$} & \multicolumn{4}{|c|}{ Pre- implementation } & \multicolumn{4}{|c|}{ Post- implementation } & \multirow[t]{3}{*}{$\mathbf{X}^{2}$} & \multirow{3}{*}{$\begin{array}{l}\mathbf{P}- \\
\text { value }\end{array}$} \\
\hline & \multicolumn{2}{|c|}{ Correct } & \multicolumn{2}{|c|}{ Incorrect } & \multicolumn{2}{|c|}{ Correct } & \multicolumn{2}{|c|}{ Incorrect } & & \\
\hline & No. & $\%$ & No. & $\%$ & No. & $\%$ & No. & $\%$ & & \\
\hline $\begin{array}{l}\text { There is harm if relationship } \\
\text { between nurse and cancer children } \\
\text { exceeds the limit of therapeutic } \\
\text { relationship. }\end{array}$ & 7 & 21.9 & 25 & 78.1 & 30 & 93.8 & 2 & 6.2 & 33.89 & $0.000 * *$ \\
\hline $\begin{array}{l}\text { A nurse should meet biological } \\
\text { and emotional needs of oncology } \\
\text { patient at the time of admission. }\end{array}$ & 12 & 37.5 & 20 & 62.5 & 30 & 93.8 & 2 & 6.2 & 22.44 & $0.000 * *$ \\
\hline $\begin{array}{l}\text { Breach in children' privacy or } \\
\text { unnecessary exposure while } \\
\text { performing a procedure constitute: } \\
\text { Invasion of privacy }\end{array}$ & 14 & 43.8 & 18 & 56.2 & 30 & 93.8 & 2 & 6.2 & 18.61 & $0.000 * *$ \\
\hline $\begin{array}{l}\text { the activity that violates the } \\
\text { patient's privacy: Talking about } \\
\text { the child in a public place }\end{array}$ & 17 & 53.1 & 15 & 46.9 & 29 & 90.6 & 3 & 9.4 & 11.13 & $0.001 * *$ \\
\hline Consents should be obtained from & 12 & 37.5 & 20 & 62.5 & 30 & 93.8 & 2 & 6.2 & 9.14 & $0.002 *$ \\
\hline
\end{tabular}




\begin{tabular}{|c|c|c|c|c|c|c|c|c|c|c|}
\hline $\begin{array}{l}\text { child's family only for operations, not } \\
\text { for nursing procedures }\end{array}$ & & & & & & & & & & \\
\hline $\begin{array}{l}\text { Every newly admitted child in the } \\
\text { oncology unit has the right for: } \\
\text { Orientation to the ward }\end{array}$ & 12 & 37.5 & 20 & 62.5 & 29 & 90.6 & 3 & 9.4 & 7.05 & $0.008 *$ \\
\hline $\begin{array}{l}\text { Admission } \\
\text { procedures in oncology unit are } \\
\text { not same as in other clinical } \\
\text { settings. }\end{array}$ & 14 & 43.8 & 18 & 56.2 & 30 & 93.8 & 2 & 6.2 & 18.61 & $0.000 * *$ \\
\hline $\begin{array}{l}\text { The primary purpose for } \\
\text { regulating pediatric cancer is to } \\
\text { protect the patient }\end{array}$ & 12 & 37.5 & 20 & 62.5 & 30 & 93.8 & 2 & 6.2 & 22.44 & $0.000 * *$ \\
\hline $\begin{array}{l}\text { oncology nurses are legally } \\
\text { obligated to keep information } \\
\text { about patient's illnesses and } \\
\text { treatment: Confidential }\end{array}$ & 10 & 31.2 & 22 & 68.8 & 28 & 87.5 & 4 & 12.5 & 20.98 & $0.000 * *$ \\
\hline $\begin{array}{l}\text { To protect the right of cancer } \\
\text { children, a nurse should have } \\
\text { knowledge about all his rights. }\end{array}$ & 16 & 50 & 16 & 50 & 29 & 90.6 & 3 & 9.4 & 12.65 & $0.000 * *$ \\
\hline
\end{tabular}

* Statistically significant at $\mathbf{P}<0.05 \quad * * A$ highly statistical significant at $\mathrm{P} \leq 0.001$

Table (2) revealed in relation to nurses' knowledge regarding their ethical responsibilities in pediatric oncology unit at pre/post-program implementation that, there were highly statistical significant differences $(\mathrm{P}<$ 0.001) toward all responsibilities at pre/post-program implementation. Meanwhile, there was no statistical significant difference regarding the right of every newly admitted child in the oncology unit to be orientated by the ward.

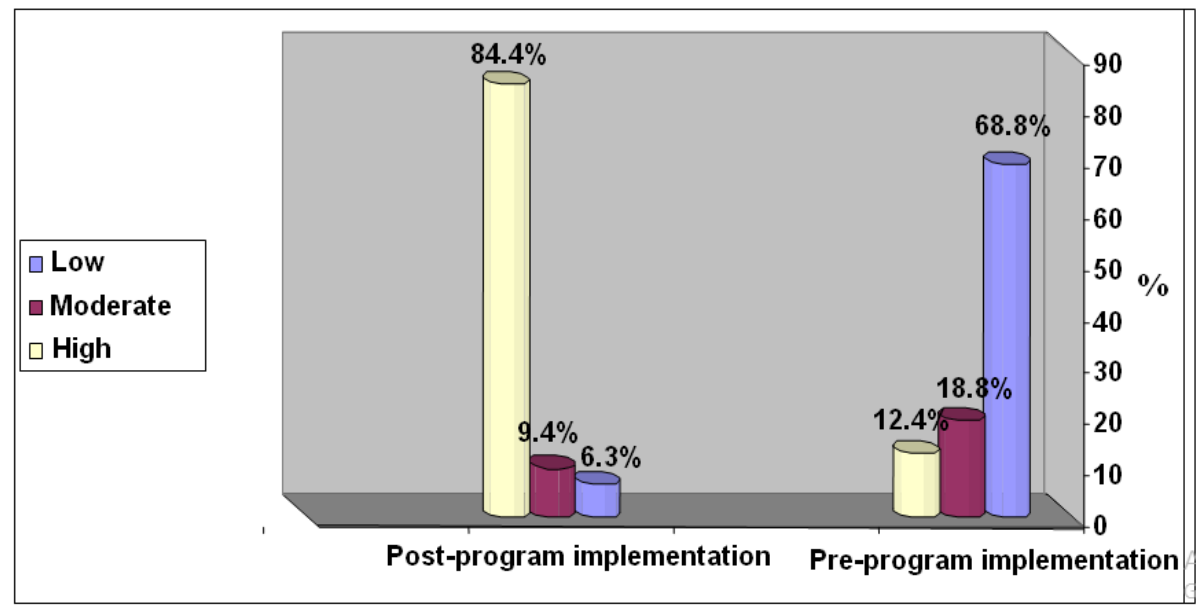

Fig. (1): Distribution of total nurses' knowledge scores regard nursing ethics in pediatric oncology unit at pre/post-program implementation $(n=32)$

Figure (1) showed regarding total scores of nurses' knowledge about nursing ethics in pediatric oncology unit pre/post program implementation that, there was an improvement in their knowledge where most of nurses $(84.4 \%)$ had good knowledge during post-program implementation. Meanwhile, at pre-program implementation only $12.4 \%$ of nurses had good knowledge.

Table (3): Distribution of nurses' ethical practice regards child's respect in Pediatric Oncology Unit at pre/post program intervention $(n=32)$

\begin{tabular}{|c|c|c|c|c|c|c|c|c|c|c|}
\hline \multirow{3}{*}{$\begin{array}{l}\text { Nurses' ethical practice } \\
\text { regards child's respect }\end{array}$} & \multicolumn{4}{|c|}{ Pre- implementation } & \multicolumn{4}{|c|}{ Post- implementation } & \multirow[t]{3}{*}{$\mathbf{X}^{2}$} & \multirow{3}{*}{$\begin{array}{l}\mathbf{P}- \\
\text { value }\end{array}$} \\
\hline & \multicolumn{2}{|c|}{ Done } & \multicolumn{2}{|c|}{ Not done } & \multicolumn{2}{|c|}{ Done } & \multicolumn{2}{|c|}{ Not done } & & \\
\hline & No. & $\%$ & No. & $\%$ & No. & $\%$ & No. & $\%$ & & \\
\hline Receiving the child during entering the unit & 14 & 43.8 & 18 & 56.2 & 32 & 100 & 0 & 0 & 25.04 & $0.000 * *$ \\
\hline Listening to any questions and giving answers & 17 & 53.1 & 15 & 46.9 & 31 & 96.1 & 1 & 3.1 & 16.33 & $0.000 * *$ \\
\hline $\begin{array}{l}\text { Talking to the child with a simple and } \\
\text { understandable manner }\end{array}$ & 20 & 62.5 & 12 & 37.5 & 32 & 100 & 0 & 0 & 14.76 & $0.000 * *$ \\
\hline $\begin{array}{l}\text { Understanding the child feeling and showing } \\
\text { empathy }\end{array}$ & 14 & 43.8 & 18 & 56.2 & 30 & 93.8 & 2 & 6.2 & 18.61 & $0.000 * *$ \\
\hline Calling the child in a suitable gentle tone & 10 & 31.2 & 22 & 68.8 & 31 & 96.9 & 1 & 3.1 & 29.93 & $0.002^{*}$ \\
\hline $\begin{array}{l}\text { Treated the child without discrimination (race, sex, } \\
\text { religion ..) }\end{array}$ & 10 & 31.2 & 22 & 68.8 & 32 & 100 & 0 & 0 & 11.85 & $0.000 * *$ \\
\hline
\end{tabular}

\footnotetext{
* Statistically significant at $\mathrm{P}<0.05 \quad * * A$ highly statistical significant at $\mathrm{P} \leq 0.001$
} 
Table (3) reflected that there was a highly statistical significant difference $(\mathrm{P}=0.000)$ between principles of nurses' ethical practice toward child's respect in pediatric oncology unit at pre/post program intervention.

Table (4): Distribution of nurses' ethical practice regards child's confidentiality in Pediatric Oncology Unit at pre/post-program intervention $(n=32)$

\begin{tabular}{|c|c|c|c|c|c|c|c|c|c|c|}
\hline \multirow{3}{*}{$\begin{array}{l}\text { Nursing ethical practice regard } \\
\text { to child's confidentiality }\end{array}$} & \multicolumn{4}{|c|}{ Pre- implementation } & \multicolumn{4}{|c|}{ Post- implementation } & \multirow[t]{3}{*}{$\mathbf{X}^{2}$} & \multirow{3}{*}{$\begin{array}{l}\mathbf{P}- \\
\text { value }\end{array}$} \\
\hline & \multicolumn{2}{|c|}{ Done } & \multicolumn{2}{|c|}{ Not done } & \multicolumn{2}{|c|}{ Done } & \multicolumn{2}{|c|}{ Not done } & & \\
\hline & No. & $\%$ & No. & $\%$ & No. & $\%$ & No. & $\%$ & & \\
\hline Not disclose information to anyone & 8 & 25 & 24 & 75 & 29 & 90.6 & 3 & 9.4 & 28.25 & $0.000 * *$ \\
\hline $\begin{array}{l}\text { Treat as confidential information } \\
\text { gained and use it for professional } \\
\text { purposes only }\end{array}$ & 10 & 31.2 & 22 & $\begin{array}{l}68 . \\
8\end{array}$ & 31 & 96.9 & 1 & 3.1 & 29.93 & $0.000^{* *}$ \\
\hline $\begin{array}{l}\text { Health records are stored securely } \\
\text { and only accessed or removed for } \\
\text { the purpose of providing care }\end{array}$ & 27 & 84.4 & 5 & $\begin{array}{l}15 . \\
6\end{array}$ & 32 & $\begin{array}{l}100 . \\
0\end{array}$ & 0 & 0 & 5.42 & $0.026^{*}$ \\
\hline
\end{tabular}

Table (4) showed that, there was a highly statistical significant difference $(\mathrm{P}=.000)$ between principles of nurses' ethical practice regard child's confidentiality in pediatric oncology unit at pre/post program intervention. Meanwhile, there was no statistical significant difference $(\mathrm{P}=.026)$ in relation to storage of health records securely.

Table (5): Distribution of nurses' ethical practice regards child's privacy in Pediatric Oncology Unit at pre/post

\begin{tabular}{|c|c|c|c|c|c|c|c|c|c|c|}
\hline \multirow[t]{3}{*}{$\begin{array}{l}\text { Nursing ethical practice } \\
\text { regard child's privacy }\end{array}$} & \multicolumn{4}{|c|}{$\begin{array}{l}\text { Pre- } \\
\text { implementation }\end{array}$} & \multicolumn{4}{|c|}{$\begin{array}{l}\text { Post- } \\
\text { implementation }\end{array}$} & \multirow[t]{3}{*}{$\mathbf{X}^{2}$} & \multirow{3}{*}{$\begin{array}{l}\mathbf{P} \text { - } \\
\text { value }\end{array}$} \\
\hline & \multicolumn{2}{|c|}{ Done } & \multicolumn{2}{|c|}{ Not done } & \multicolumn{2}{|c|}{ Done } & \multicolumn{2}{|c|}{ Not done } & & \\
\hline & No. & $\%$ & No. & $\%$ & No. & $\%$ & No. & $\%$ & & \\
\hline $\begin{array}{l}\text { Discuss the child health condition with the } \\
\text { medical team in privacy }\end{array}$ & 6 & 18.8 & 26 & 81.2 & 30 & 93.8 & 2 & 6.2 & $\begin{array}{l}36.5 \\
7\end{array}$ & $0.000 * *$ \\
\hline $\begin{array}{l}\text { Taking the child and her family permission } \\
\text { before entering the visitors }\end{array}$ & 5 & 15.6 & 27 & 84.4 & 27 & 84.4 & 5 & 15.6 & $\begin{array}{l}30.2 \\
5\end{array}$ & $0.000^{* *}$ \\
\hline $\begin{array}{l}\text { Don't interrupted the child during sleep except } \\
\text { for giving care }\end{array}$ & 7 & 21.9 & 25 & 78.1 & 29 & 90.6 & 3 & 9.4 & $\begin{array}{l}30.7 \\
3\end{array}$ & $0.000 * *$ \\
\hline $\begin{array}{l}\text { Closing windows, door and covering the child or } \\
\text { putting curtains during check-up or giving the } \\
\text { care }\end{array}$ & 19 & 59.4 & 13 & 40.6 & 26 & 81.2 & 6 & 18.8 & 3.66 & $0.05^{*}$ \\
\hline
\end{tabular}

* Statistically significant at $\mathbf{P}<0.05 \quad * * A$ highly statistical significant at $\mathbf{P} \leq 0.001$

Table (5) displayed that, there were statistical significant differences in relation to nurses' ethical practice regarding child's privacy in pediatric oncology unit at pre/post-program implementation.

Table (6): Distribution of nurses' ethical practice regards child's beneficence in Pediatric Oncology Unit at

\begin{tabular}{|c|c|c|c|c|c|c|c|c|c|c|}
\hline \multirow[t]{3}{*}{$\begin{array}{l}\text { Nursing ethical practice } \\
\text { regards child's beneficence }\end{array}$} & \multicolumn{4}{|c|}{$\begin{array}{l}\text { Pre- } \\
\text { implementation }\end{array}$} & \multicolumn{4}{|c|}{$\begin{array}{l}\text { Post- } \\
\text { implementation }\end{array}$} & \multirow[t]{3}{*}{$\mathbf{X}^{2}$} & \multirow[t]{3}{*}{$\begin{array}{l}\mathbf{P}- \\
\text { value }\end{array}$} \\
\hline & \multicolumn{2}{|c|}{ Done } & \multicolumn{2}{|c|}{ Not done } & \multicolumn{2}{|c|}{ Done } & \multicolumn{2}{|c|}{ Not done } & & \\
\hline & No. & $\%$ & No. & $\%$ & No. & $\%$ & No. & $\%$ & & \\
\hline $\begin{array}{l}\text { Create a safe and supportive } \\
\text { environment }\end{array}$ & 12 & 28 & 20 & 62.5 & 28 & 87.5 & 4 & 12.5 & 17.06 & $0.000 * *$ \\
\hline Prevent harm to child & 17 & 53.1 & 15 & 46.9 & 27 & 84.4 & 5 & 15.6 & 7.27 & $0.007 *$ \\
\hline Help child in his crises & 10 & 31.2 & 22 & 68.8 & 23 & 71.9 & 9 & 28.1 & 10.57 & 0.001 ** \\
\hline
\end{tabular}

* Statistically significant at $\mathbf{P}<0.05 \quad * * \mathbf{A}$ highly statistical significant at $\mathbf{P} \leq \mathbf{0 . 0 0 1}$

Table (6) clarified that, there was a highly statistical significant difference $(\mathrm{P}<.000)$ between principles of nurses' ethical practice regards child's beneficence in pediatric oncology unit at pre/post program implementation. 


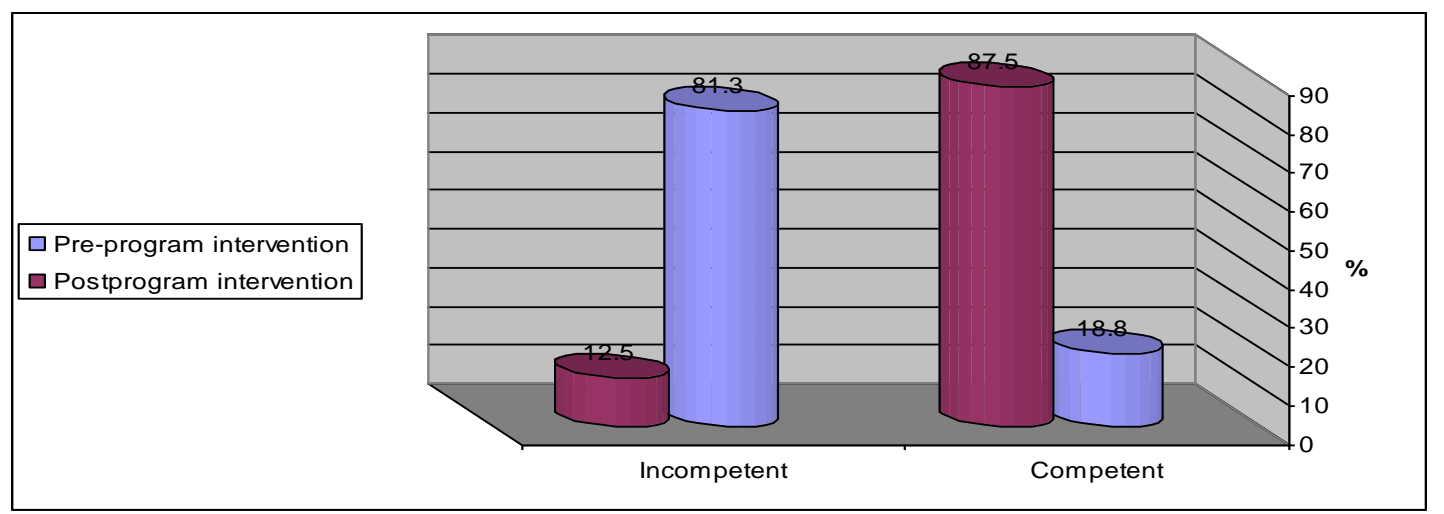

Fig. (2): Distribution of total nurses' practice scores regards follow the application of ethical principles in nursing care at pre/post-program implementation

According to the total scores of nurses' practice regards follow the application of ethical principles in nursing care in pediatric oncology unit at pre/post-program implementation figure (2) revealed that, $87.5 \%$ of nurses had competent practice at post-program implementation. Meanwhile, $12.5 \%$ of them had competent practice at pre-program implementation.

Table (7): Correlation coefficient between nurses' knowledge and practice regarding nursing ethics in Pediatric Oncology Unit at Pre/Post Program Implementation $(n=32)$

\begin{tabular}{|l|l|l|l|l|}
\hline Nurses' knowledge regarding ethics & \multicolumn{4}{|l|}{ Nurses' practice regarding ethics } \\
\cline { 2 - 5 } & $\begin{array}{l}\text { Pre- Program } \\
\text { Implementation }\end{array}$ & \multicolumn{2}{l|}{ Post- Program Implementation } \\
\cline { 2 - 5 } & $\mathbf{r}$ & $\mathbf{p}$ & $\mathbf{r}$ & $\mathbf{p}$ \\
\cline { 2 - 5 } & .891 & 0.000 & .984 & 0.000 \\
\hline
\end{tabular}

Table (7) indicated that, there was a positive correlation between nurses' knowledge and practice regarding nursing ethics in pediatric oncology unit at pre/post program implementation where $r=.984, \mathrm{P}<0.001$.

Regarding the relation between nurses' knowledge about nursing ethics and their personal characteristics, the present study findings showed that there was no significant association $(P>0.05)$ found between nurses' knowledge and their age, job, qualification and years of experience, while attending ethical courses in pediatric oncology unit was significantly associated with the level of nurses' knowledge.

Moreover, the current study results revealed that there was statistical significant relationship $(\mathrm{P}<0.001)$ between nurses' practice regarding nursing ethics and their age, qualification, years of experience and attending ethical courses in pediatric oncology.

\section{Discussion}

Oncology nurses are frequently in need to encounter ethical issues in their everyday practice because of the complex needs of patients, especially in pediatric oncology where the number, presentation and type of oncologic processes usually differ from those seen in adult oncology (Moore et al., 2014). In addition, as nurse's knowledge and skills are important forces that can contribute to the power to influence patient care in an ethical manner. Therefore, the present study was aimed to evaluate the effect of guideline about ethics on nurses' knowledge and performance in pediatric oncology unit.

The results of the present study revealed that, the aim was achieved through the utilization of guideline educational program on nursing ethics by the nurses which motivated them to integrate ethics in providing competent care at pediatric oncology unit.

In this study, regarding nurses' ethics knowledge at pre and post-program intervention, the findings showed that the overall level of nurses' knowledge was significantly improved with the program. It is inferred that the guideline program helped nurses to improve their knowledge in nursing ethics that confronted them during their work in pediatric oncology unit related to nursing ethical principles such as beneficence, consent, autonomy, veracity, justice, and confidentiality. In this regard Kumar et al. (2011) conduct study about knowledge of staff nurses regarding legal and ethical responsibilities in the field of psychiatric nursing, they demonstrated that it is necessary to intensify efforts to ensure that staff nurses who are involved in providing quality health care services have acquire necessary knowledge about the legal and ethical issues in nursing practice. However, this finding was supported in the study done by Bartholdson, (2015) about 'Clinical ethics in childhood cancer care: the value of inter-professionally shared reflection, who found that nurses' participation in inter-professional dialogue and 
educational sessions regarding an ethical issues improve their awareness about ethics that required in their practice.

In the same context the present study revealed that, there was highly significantly improvement in nurse's ethics knowledge regarding meaning, importance and principles of ethics after intervention of the guideline educational program about ethics. In this respect Storch et al., (2011) found in his study that done about listening to nurses moral voice: building a quality health care environment, that providing nurses with books and articles abundant with descriptions of nursing ethics improve their awareness about the meaning and significance and principles of nursing ethics in their daily practices.

As regard nurses' ethical practice the current study findings revealed that, there was statistical significant improvement in nurses' practice regarding all ethical principles related to child's respect, privacy, confidentiality, beneficence, justify and clinical integrity where the majority of nurses had competent practice at post-program intervention. This could be due to increase the nurses' knowledge regard nursing ethics was an important contributor for improvement in nurses' practice. This finding was agreed with the study done by Zakaria et al., (2016) studied effectiveness of ethical issues teaching program on knowledge, ethical behavior and ethical stress among nurses, they reported that, there was highly statistical significant in improvement of nurses' ethical behaviors in their practice before and after the teaching program immediately and after 3 months of teaching program. In the same regard Shrestha \& Jose, (2014) added in their study about knowledge and practice of nursing ethics and laws, that more than half of nurses have adequate practice regard applying ethics in their care for patients.

The result of the present study clarified that, there was a positive correlation between nurses' knowledge and practice regarding nursing ethics toward children in pediatric oncology unit at post program intervention. This indicates that, the improvement in nurses' knowledge after program lead to improvement in their practice. In this regard Donkor \& Andrews, (2011) revealed in their study about ethics, culture and nursing practice, that nurses' application of available ethical codes has dependent on their knowledge about the ethic codes. Also Gastmans, (2012) conduct study about fundamental ethical approach to nursing, he added that there is a strong correlation between nurses' knowledge and practice regard nursing ethics as insufficient exposures to adequate educational programs regarding nursing ethics has been cited as contributing to poor ethical responsibilities of nurses and a lack of commitment to ethics. In addition, Silen et al., (2014) conduct study about Ethics rounds: An appreciated form of ethics support, they confirmed that any gaps in nurses' knowledge regarding nursing ethics can affect positively their best nursing care. However, this finding was supported by Zakaria et al., (2016) they found that there was strong correlation between nurses' knowledge of nursing ethics and their ethical behavior after the implementation of the program.

According to the relation between nurses' knowledge on nursing ethics and their personal characteristics, the findings of this study revealed that, there was no significant association found between nurses' knowledge and their age, job, qualification and years of experience, while attending ethical courses in pediatric oncology unit was significantly associated with the level of nurses' knowledge. This result was supported by McLennon et al., (2013) who studied oncology nurses' narratives about ethical dilemmas and prognosis-related communication in advanced cancer patients, they found that attending in-service training program on nursing profession ethics can promote nurses' knowledge regarding ethics.

As regard to the relation between nurses' practice and their personal characteristics, the present study showed that, there was statistical significant relationship between nurses' practice regarding nursing ethical principles and their age, qualification and years of experience. This finding was supported by Aghdam et al., (2013) who illustrated in the study done about "Knowledge and performance about nursing ethic codes from nurses' and patients' perspective in Tabriz Teaching Hospitals" that, there was significant relationship between nurses' ethical performance and their age and information resources such as participating in seminars, continuous education and regulation but no significant relationship with work history and marital status.

\section{Conclusion}

In the light of the present study findings, it concluded that, there was a highly significant improvement in nurses' knowledge and practice after application of the intervention compared to pre-intervention assessment regard nursing ethics.

\section{Recommendations}

Based on the findings of the present study, the following recommendations are suggested to be implemented:

- Encourage nurses to attend training courses about ethical responsibilities toward children in oncology unit.

- Periodical evaluation for nurses' practice to ensure application of ethical principles in nursing care. 
- Regular pre-service and in-service educational programs must be developed and implemented for nurses to improve their ethical awareness and improve their abilities to utilize ethical issues in other pediatric units in the hospital.

\section{References}

[1]. Aghdam A.M., Hassankhani H., Zamanzadeh V., Khameneh S., and Moghaddam S., (2013): Knowledge and performance about nursing ethic codes from nurses' and patients' perspective in Tabriz Teaching Hospitals, Iran, Journal of Caring Sciences; 2(3): 219227.

[2]. Ahmed I.S., (2010): The relationship between nursing staff and patient's perception toward patient's rights and patient's satisfaction of nurses' compliance, Unpublished master thesis, Faculty of Nursing, Benha University: pp. 48-54.

[3]. Aliyu D., Adeleke I.T., Omoniyi S.O., Samaila B.A., Adamu A., and Abubakar A.Y., (2015): Knowledge, attitude and practice of nursing ethics and law among nurses at Federal Medical Centre, Bida, American Journal of Health Research; 3(1-1): 32-37.

[4]. American Cancer Society, (2012): Cancer; Basic Facts. http://www.cancer.org/downloads/STT/CancerFacts\&Figures2012M.pdf. Accessed; December 9 2014.
American Medical Association, (2010): Code of Medical Ethics, Available at; http://www.ama-assn.org/ama/pub/physicianresources/medical-ethics/code-medical-ethics.shtml

[6]. American Nurses Association, (2015): Code of ethics for nurses with interpretive statements. Retrieved from; http://www.nursingworld.org/MainMenuCategories/EthicsStandards/CodeofEthicsforNurses

[7]. Association of Pediatric Hematology/Oncology Nurses, (2011): Scope and Standards of Pediatric Oncology Nursing Practice, Silver Spring, Md, Nursesbooks.org, 2011, Available at; http://www.apon.org/i4a/pages/index.cfm? Retrieved April 30, 2014.

[8]. Bartholdson C., (2015): Clinical ethics in childhood cancer care: The value of inter-professionally shared reflection, Karolinska Institute, Stockholm, Sweden, pp. 32-49.

[9]. Blogger C., and Moore J.A., (2010): Pediatric Ethics, University of Texas, MD Anderson Cancer Center, Available at; nectur@mdanderson.org.

[10]. Cherry B., and Jacob S., (2008): Contemporary nursing, ethical issues, trends, management, $3^{\text {rd }}$ ed., Elsevier Mosby, New York: p.181.

[11]. Children's Oncology Group, (2010): Emotional issues after childhood cancer, Healthy living after treatment for childhood cancer, Emotional issues, Version 3.0-10/08, pp. 1-6, Available at; www.survivorshipguidelines.org

[12]. Donkor N.T., and Andrews L.D., (2011): Ethics, culture and nursing practice in Ghana, International Nurse Review; 58(1): 109 114.

[13]. Ellis-Christensen T., (2010): What is Pediatric oncology?. Retrieved from http://www.wisegeek.com/what-is-pediatriconcology.htm

[14]. Erickson J.M., and Payne K., (2016): Ethics in Oncology Nursing, Oncology Nursing Society, Oxford University Press, P. 200.

[15]. Gastmans C.A., (2012): Fundamental ethical approach to nursing: some proposals for ethics education, Nurse Ethics; 9(5): $494-507$.

[16]. Kearney J.A., and Lederberg S.M., (2014): Nursing ethics, Ethical issues in pediatric oncology, Chapter 16, Oxford University Press, pp. 411-26.

[17]. Kopelman L.M., (2013): Using the best interests' ethical standard in treatment decisions for young children. In: G. Miller, Pediatric bioethics. New York: Cambridge University Press: pp. 22-37.

[18]. Kumar R., Mehta S., and Kalra R., (2011): Knowledge of staff nurses regarding legal and ethical responsibilities. Nursing and Midwifery Research Journal; 7(1): 133-137.

[19]. McLennon S.M., Uhrich M., Lasiter S., Chamness A.R., and Helft P.R., (2013): Oncology nurses' narratives about ethical dilemmas and prognosis-related communication in advanced cancer patients, Cancer Nurse; 36(2):114-121.

[20]. Mohajjel-Aghdam A., Hassankhani H., Zamanzadeh V., Khameneh S., Moghaddam S., (2013): Knowledge and performance about nursing ethic codes from nurses' and patients' perspective in Tabriz Teaching Hospitals, Iran, Published thesis, PubMed, Journal Caring Science. 2013 Aug 28; 2(3):219-27.

[21]. Mohamed D., (2006): Patients' and physicians' perception of patients' rights in two general hospitals in Alexandria, Master thesis, High institute of public health, Alexandria University, pp. 61-72.

[22]. Momennasab M., Koshkaki A.R., Torabizadeh C., and Tabei S.Z., (2015): Nurses' adherence to ethical codes in oncology units: The viewpoints of patients, nurses and managers, Nursing; 22(1): 131-152.

[23]. Moore J., Engel J., and Prentice D., (2014): Relational ethics in everyday nursing practice, Canadian Oncology Nursing Journal; 24(1): 31-34.

[24]. Seoul M.P., Jeon S.H., and Hong H.J., (2014): A comparison of ethical issues in nursing practice across nursing units, Nursing Ethics; 21(5): 594-607.

[25]. Shrestha S., and Jose P., (2014): Knowledge and practice of nursing ethics and laws, Journal of Universal College of Medical Sciences; 02 (03) 07: 30-33.

[26]. Silen M., Ramklint M., Hansson M.G., and Haglund K., (2014): Ethics rounds: An appreciated form of ethics support. Nurse Ethics; 17(4): 211-214.

[27]. Stegenga K.A., (2015): Special patients need special nurses, Journal of Pediatric Oncology Nursing; 33(3): 96-99.

[28]. Storch J.L., Rodney B., Brown H., and Starzomski R., (2011): Listening to nurses moral voice: Building a quality health care environment. CJNL; 15(4): 117-126.

[29]. Sundean L.J., and McGrath J.M., (2013): Ethical considerations in the neonatal intensive care unit, Newborn \& Infant Nursing Reviews; 13 (4): 117-120.

[30]. Zakaria A.M., Sleem W.F., and Seada A.M., (2016): Effectiveness of ethical issues teaching program on knowledge, Journal of Nursing Education and Practice; 6(7): 134-152. 